This item was submitted to Loughborough's Research Repository by the author.

Items in Figshare are protected by copyright, with all rights reserved, unless otherwise indicated.

\title{
Why should a firm choose to limit the size of its market area?
}

PLEASE CITE THE PUBLISHED VERSION

PUBLISHER

(c) Loughborough University

VERSION

VoR (Version of Record)

LICENCE

CC BY-NC-ND 4.0

\section{REPOSITORY RECORD}

Alderighi, Marco, and Claudio Piga. 2019. "Why Should a Firm Choose to Limit the Size of Its Market Area?". figshare. https://hdl.handle.net/2134/4262. 
This item was submitted to Loughborough's Institutional Repository (https://dspace.lboro.ac.uk/) by the author and is made available under the following Creative Commons Licence conditions.

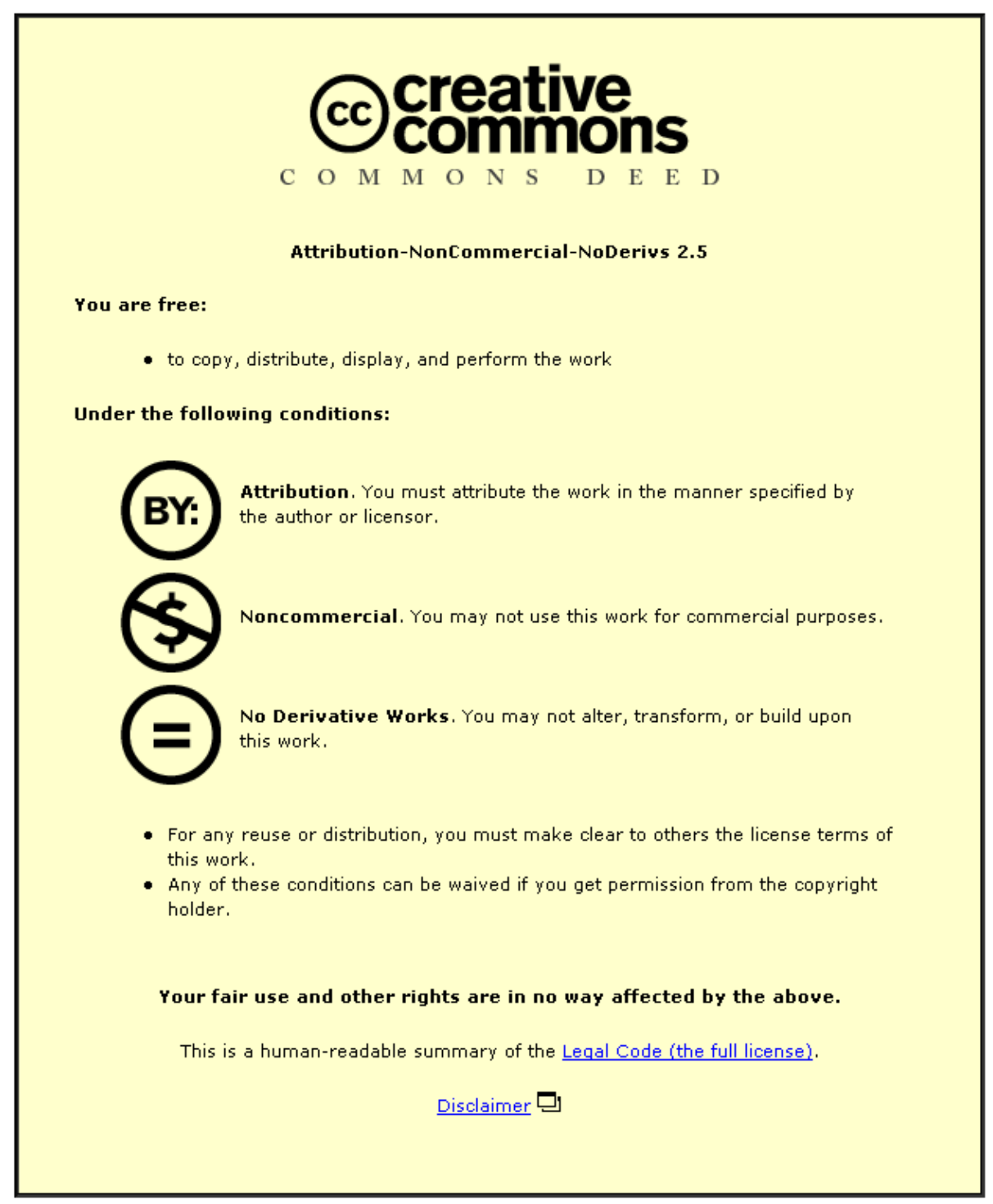

For the full text of this licence, please go to: http://creativecommons.org/licenses/by-nc-nd/2.5/ 
ISSN 1750-4171

\section{DEPARTMENT OF ECONOMICS}

\section{DISCUSSION PAPER SERIES}

\section{Why Should a Firm Choose to Limit the Size of its Market Area?}

Marco Alderighi

Claudio A. Piga

\section{WP 2007 - 21}

Dept Economics

Loughborough University

Loughborough

LE11 3TU United Kingdom

Tel: + 44 (0) 1509222701

Fax: + 44 (0) 1509223910

http://www.lboro.ac.uk/departments/ec 


\title{
Why Should a Firm Choose to Limit the Size of its Market Area?
}

\author{
Marco Alderighi* \\ Università della Valle d'Aosta, Italy. \\ Università Bocconi, Milano, Italy. \\ m.alderighi@univda.it
}

\author{
Claudio A. Piga \\ Department of Economics \\ Loughborough University \\ c.a.g.piga@lboro.ac.uk
}

August 8, 2007

\begin{abstract}
We study when a monopolistically-competitive firm may optimally choose to limit the size of its market. This may be the case when the cost of serving the market with geographically dispersed customers is increasing in size. We also investigate the incentives faced by a firm to limit the reach of its market, when it adopts different pricing schemes. We show that under certain assumptions the derived equilibria are constrained socially optimal.
\end{abstract}

JEL classification: D21, D43, F12, L13, R12.

Keywords: Monopolistic competition; Transport costs; Endogenous fixed costs; Overlapping market areas

\footnotetext{
${ }^{*}$ Corresponding Author: Address: Strada Cappuccini, 2A, 11100 Aosta, Italy - Tel: +39 0165306711 Fax: +390165 32835 - e-mail: m.alderighi@univda.it.
} 


\section{Introduction}

In traditional models of spatial competition based on Hotelling (1929) a firm has no advantage in limiting its spatial coverage. However, in many real-world situations, the choice of the market reach is voluntary. For example, a firm chooses the size of its market area when it decides whether to open a new store, to enter a new market, to advertise its products, to develop a distributional channel, or to cream-skim consumers.

In this paper we use a modified version of the standard framework proposed by Dixit and Stiglitz (1977), where firms and consumers face transport costs and firms can choose reach, quality and price. In this setup, firms operate in a monopolistically competitive market: product differentiation ensures that a firm retains some market power, but even with the cheapest delivered price, it is no longer the exclusive supplier. A stylized example of the model's characteristics we present pertains to the tourist industry. Imagine that the historical towns in Europe compete with each other in attracting visitors from around the world. Each town faces transport costs in the form of advertising aimed at informing the tourists about its attractions. If the campaign's effectiveness decreases with distance, then a town may choose to limit its market coverage. This effect is reinforced if also tourists' transport costs increase with distance, as one would normally expect.

The model is solved assuming two different pricing mechanisms. Under spatial price discrimination, a firm may choose to limit its market coverage only when endogenous fixed costs are increasing in reach. Under uniform pricing, the coverage may be limited also when fixed costs are not affected by reach, if unit variable costs are increasing in reach. The contrast arises because in the first case increases in production costs can be perfectly passed on to consumers, while in the second they cannot. In both settings, consumers' transport costs push towards a reduction of the market size and enhance the profitability of a strategy focussing on the more captive consumers. Finally, we show that the firm's behaviour determines a constrained socially optimum equilibrium, i.e, it corresponds to the outcome that an industry regulator would impose.

As a real-world case of competition involving firms that limit their reach, consider the Italian furniture districts of Prato, Biella, Brianza, Como and Pesaro. They consist of a few leading firms (e.g., Cassina, Molteni, B\&B, Scavolini, etc.) and a myriad of independent firms which export their Italian-styled furniture around the world. A survey of 187 small exporters reveals that 161 of these sell to EU countries, 109 to East Europe, 97 to Americas, 66 to China and 80 to the rest of the world (Bramanti, 2007). Among these, only 3 firms play globally, but 102 operate at least in three macro-areas. Excluding the EU market, 163 
firms export to other macro-areas; the number of competitors which a firm faces at least in one market remains rather high (on average 125 competitors). This example illustrates a couple of stylized facts that are included in our analysis. First, most of the firms do limit their reach. Second, firms do not exactly compete for the same markets, but their market areas do partially overlap. ${ }^{1}$

A great deal of economic analysis has focussed on the impact of reach on costs. The international trade literature shows that firms encounter important costs from being international. In fact, Rabino (1980) and Kedia and Chhokar (1986) found that logistic and transport costs, the complexity of paperwork, the problems from understanding and managing export procedures and foreign business practices, the need to modify products to meet foreign safety and health standards, engender important costs, especially to small manufacturing companies. These findings are confirmed in more recent studies (McAuley, 1993, and Katsikeas and Morgan, 1994, 1998). McCallum (1995), in analyzing the trade among regions on the U.S.-Canada border, showed that the impact of borders on trade is quite large, even if the two countries are similar in terms of culture, language, and institutions. Other studies on border effects provide many interpretations. For example, Rauch (1996) suggested that there are 'search' barriers, especially for differentiated products. Anderson and van Wincoop (2001) stated that border barriers generate trade costs, which "involve real resources, such as gathering information about foreign regulations, hiring lawyers familiar with foreign laws, learning foreign languages and adjusting product designs to make them consistent with foreign customs and regulations." Bandyopadhyay (1999) analyzed distribution sectors in OECD countries and showed that high distribution costs can be a barrier to trade and limit the extent of spatial coverage. In informative advertising models, Grossman and Shapiro (1984) considered the case where oligopolistic firms and monopolistically-competitive firms are able to choose the amount of purely informative advertising (i.e., the fraction of consumers they want to inform) and assume that the costs of advertising technology are increasing in reach. Under these assumptions, they show that it may be optimal to limit the coverage. In regulation literature, public utilities encounter different costs for serving different types of customers (for example, urban and rural customers) and, if allowed, firms choose to cream-skim costumers (Laffont and Tirole, 1990).

This paper is related to the stream of new economic geography literature (for a survey, see,

\footnotetext{
${ }^{1} \mathrm{~A}$ spatio-temporal interpretation of the same stylised facts is provided by the taxi market in a town. Consumers value variety, i.e. the opportunity of hiring a taxi whenever they need and wherever they are. Taxis usually choose to limit their market size (for example, they do not serve potential customers who cannot be reached within 5 minutes). As consumers and taxis move around the town, competition on a single consumer concerns only few taxis even if in general all taxis compete with each other.
} 
for example: Ottaviano and Puga, 1998) and, in particular, with the core-periphery model (Krugman, 1980 and Helpman and Krugman, 1985, Ch. 10), where firms' and consumers' transport costs play a crucial role. However, our contribution is different in several ways. First, we do not set the model in a two-country framework, but, rather, in a continuous framework. Thus, transport costs vary with the relative location of consumers and firms. Second, in the core-periphery models, it is optimal for firms to serve the entire market. Transport costs only distort the consumption in favor of home production, while in our model with increasing costs of reach, firms can optimally choose to serve only a portion of the market.

In models of spatial competition, firms usually serve customers exclusively (Kohlberg, 1983; Parr, 1995; Piga and Poyago-Theotoky, 2005; Wong and Yang, 1999). We depart from this assumption by letting the same place be part of the catchment area of different firms (Anderson and de Palma, 2000; Drezner and Drezner, 1996)

The remainder of this paper is organized as follows. In Section 2 introduces the model: Sections 2.1 and 2.2 show its short- and long-term solution under the assumptions of spatial price discrimination and uniform pricing, respectively. Section 3 derives the condition for which the previous equilibria are a constrained optimum from a social point of view. Finally, Section 4 concludes.

\section{The Model}

Market area. Let $M$ be the number of firms and $s_{i} \in \mathcal{S}_{i} \equiv[0,1]$ denotes the size of the market area, or reach, that firm $i \in M$ wants to serve. Each firm can decide to sell its product on the entire market (i.e., $s_{i}=1$ ) or to focus on a portion of the market (i.e., $s_{i}<1$ ). Consumers have unitary mass and each is indexed by $\omega \in \Omega \equiv[0,1]$. However, consumers are heterogeneous for each firm, in the sense that each firm $i$ ranks each consumer differently. That is, each consumer's position is defined in accordance to a firm-specific permutation function that randomly determines firm $i$ 's rank of consumer $\omega$. I.e., $T_{i}: \Omega \rightarrow \mathcal{S}_{i}$, or, $\tilde{s}_{i}=T_{i}(\omega)$. This implies that for any $\tilde{s}_{i} \leq s_{i}$, consumer $\omega=T_{i}^{-1}\left(\tilde{s}_{i}\right)$ belongs to firm $i$ 's market area $S_{i}:=\left[0, s_{i}\right]$. Furthermore, for each pair of firm $i$ and $k$, the distributions of consumers generated by $T_{i}$ and $T_{k}$ are perfectly independent, implying that consumers are randomly positioned across the firms' market areas. However, all the firms compete with each other even when they do not serve the entire market. ${ }^{2}$ The following example clarifies

\footnotetext{
${ }^{2}$ This formulation is similar to Hart (1985), where the focus is however on consumers and not on firms. In fact, Hart (1985) assumes that consumers like only a finite subset of brands which are potentially available,
} 
this set-up.

Example 1 There are 12 consumers labeled $\Omega \equiv\{a, b, c, d, e, f, g, h, i, j, k, l\}$ and $M=4$ firms. Assume $s_{i}=3 / 4$. Applying $T_{i}: \Omega \rightarrow \mathcal{S}_{i}$ yields the following market areas:

$$
\begin{aligned}
& S_{1}=\{a, b, c, d, e, f, g, h, i\} \quad S_{3}=\{k, f, c, a, j, d, l, b, e\} \\
& S_{2}=\{g, h, e, l, f, i, k, d, j\} \quad S_{4}=\{i, b, l, g, a, k, c, h, j\}
\end{aligned}
$$

The position in $S_{i}$ denotes a decreasing position in the ranking of firm i's preferences. Moreover, note that despite the limited market areas, all firms compete among each other.

Consumer demand. Let $q_{i} \in[0,1]$ be the quality offered by firm $i$ and $p_{i}>0$ be the monetary price paid by the consumer. Each consumer $\omega$ has preferences for all brands described by a constant elasticity of substitution (CES) utility function:

$$
u_{\omega}=\left(\sum_{i=1}^{M} \mathcal{I}_{\left\{T_{i}(\omega) \in S_{i}\right\}}\left(x_{i} t_{i} q_{i}\right)^{\rho}\right)^{1 / \rho}=\left(\sum_{j=1}^{N}\left(x_{j} t_{j} q_{j}\right)^{\rho}\right)^{1 / \rho}
$$

where $\mathcal{I}_{\left\{T_{i}(\omega) \in S_{i}\right\}}$ is the indicator function, which assumes 1 when $T_{i}(\omega) \in S_{i}$ and 0 otherwise, $\rho \in(0,1)$ is such that $\sigma=1 /(1-\rho)$ is the elasticity of substitution between any two products, $N$ is the number of varieties that consumer $\omega$ can buy, $j \in N$ refers to a firm whose market area includes consumer $\omega$, and $x_{j}$ and $q_{j}$ are, respectively, the quantity and the quality provided by firm $j$ to consumer $\omega$. Consumers' transport costs will be assumed to be of the 'iceberg' type; that is, only a fraction $t_{j} \leq 1$ of the goods shipped by firm $j$ arrives to consumer $\omega$. Note that $t_{j}$ depends on the position of consumer $\omega$ in firm $j$ 's market area. That is $t_{j}=t\left(T_{j}(\omega)\right)=t(\tilde{s})$ with $t^{\prime} \leq 0$, i.e., the more the customer is preferred by the firm, the lower the transport costs. ${ }^{3}$

Note that we can interpret the market size area $s_{i}$ as the probability for consumer $\omega$ of belonging to the market area of firm $i$, hence $N=\sum_{i=1}^{M} s_{i}$. (For simplicity, the integer number problem is omitted). The consumer budget constraint is: $\sum_{j=1}^{N} p_{j} x_{j}=I$, where $I$ is the expenditure for the goods. The demanded quantity (gross of shipping costs) by consumer $\omega$ from firm $j$, namely $x_{j}$, is:

$$
x_{j}\left(q_{j}, p_{j}, t_{j}\right)=\left(q_{j}\right)^{\frac{\rho}{1-\rho}} \cdot p_{j}^{-\frac{1}{1-\rho}} \cdot X P^{\frac{1}{1-\rho}} \cdot\left(t_{j}\right)^{\frac{\rho}{1-\rho}}=\hat{x}_{j}\left(q_{j}, p_{j}\right) \cdot \tau_{j}
$$

and that this subset is generally different for different consumers.

${ }^{3}$ For instance, on eBay many retailers differentiate the delivery cost depending on the postal code of the buyers. 
where $X:=\left(\sum_{j=1}^{N}\left(x_{j} t_{j} q_{j}\right)^{\rho}\right)^{1 / \rho}$ and $P:=\left(\sum_{j=1}^{N}\left(p_{j} / t_{j} q_{j}\right)^{-1 / \beta}\right)^{-\beta}$ are respectively the quantity index and the price index and $\beta:=(1-\rho) / \rho$ is inversely related to the elasticity of substitution. ${ }^{4}$ Consumer's demand is the result of two factors: $\hat{x}_{j}\left(q_{j}, p_{j}\right)=\left(q_{j}\right)^{\frac{\rho}{1-\rho}} \cdot p_{j}^{-\frac{1}{1-\rho}}$. $X P^{\frac{1}{1-\rho}}$, that captures the quantity demanded as a function of prices and quality but not of transport costs and $\tau_{j}:=t_{j}^{\rho /(1-\rho)} \leq 1$ which represents the negative impact of transport costs on quantity demanded.

Variable costs. Unit variable costs are $c\left(\tilde{s}_{i}, q_{i}\right)=q_{i}^{\theta} g\left(\tilde{s}_{i}\right), g>0, g^{\prime}, g^{\prime \prime} \geq 0$. They include the cost of producing, customizing, and delivering one unit of good of quality $q_{i}$ to a generic consumer $\tilde{s}_{i} \in S_{i}$. The elasticity of variable costs with respect to quality is given by $\theta \in[0,1)$. Because $\partial^{2} c / \partial q_{i}^{2}<0$, then the unit variable costs increase proportionally less than the quality perceived by consumers. This modelling choice is similar to that of Shaked and Sutton (1987), where "the costs of quality improvement involve at most only a modest rate of increase in unit variable cost. (p. 136)". Summing up, total variable costs are:

$$
C\left(s_{i}, q_{i}\right)=\int_{0}^{s_{i}} c\left(\tilde{s}_{i}, q_{i}\right) x_{i}\left(\tilde{s}_{i}, q_{i}, t_{i}\right) d \tilde{s}_{i} .
$$

Fixed costs. Fixed costs, denoted by $h\left(s_{i}, q_{i}\right)$ are unrelated to the production level, but depend on the choice of reach and quality. They account for costs accruing from acquiring information on foreign markets, understanding export procedures and foreign business practices, advertising, post-sale and return policy, $\mathrm{R} \& \mathrm{D}$ expenditures as well as costs involving product design to meet foreign safety and health standards. Let $h>0$ and $h_{s}, h_{q}, h_{s s}, h_{q q} \geq 0$.

Economies of size. Denote $\bar{h}\left(s_{i}, q_{i}\right)=h\left(s_{i}, q_{i}\right) / s_{i}$ as the fixed costs divided by the size of the market area, or, simply, average fixed costs.

Definition 1 The function $\bar{h}\left(s_{i}, q_{i}\right)$ exhibits (dis)economies of size when, by expanding the reach $s_{i}$, the average fixed costs decrease (increase), i.e.

$$
\frac{\partial \bar{h}\left(s_{i}, q_{i}\right)}{\partial s_{i}}=\frac{h\left(s_{i}, q_{i}\right)}{s_{i}}-\frac{\partial h\left(s_{i}, q_{i}\right)}{\partial s_{i}}>(<) 0
$$

Note that equation (4) is analogous to the definition of economies of scale in standard microeconomic analysis. Let $s^{m}$ be the market size that minimizes the average fixed cost for a given quality $q$, that is, $s^{m}=\arg \min _{s} \bar{h}(s, q)$. Figure 1 depicts the two only possible occurrences: in panel (a), there are economies of size in the range $\left[0, s^{m}\right)$ and diseconomies

\footnotetext{
${ }^{4}$ On how to derive and interpret equation (2), see Dixit and Stiglitz (1977).
} 
of size in the range $\left(s^{m}, 1\right]$; in panel (b), there are only economies of size. Since $h>0$ and continuous, there are no situations where there are diseconomies of size for all $s$.

Insert Figure 1 about here

In the two following sections, we solve the model under two different pricing schemes: spatial price discrimination and uniform pricing. In either cases the market equilibrium in a monopolistic competitive structure is derived using the zero-profit entry condition.

\subsection{Firm supply under spatial price discrimination}

Recall how $T_{i}$ defines firm $i$ 's ranking of consumers in its market area. Spatial price discrimination entails that the firm can charge each consumer differently depending on the latter's position in the ranking.

The profit of firm $i$ is given by the following expression:

$$
\pi_{i}\left(s_{i}, q_{i}, p_{i}\right)=\int_{0}^{s_{i}}\left(p_{i}(\tilde{s})-c\left(\tilde{s}, q_{i}\right)\right) \cdot \hat{x}_{i}\left(q_{i}, p_{i}(\tilde{s})\right) \cdot \tau(\tilde{s}) d \tilde{s}-h\left(s_{i}, q_{i}\right)
$$

Firm $i$ maximizes (5) by simultaneously choosing three strategic variables: price, quality and size of the market area. First order conditions imply that:

$$
\begin{gathered}
p_{i}\left(\tilde{s}_{i}, q_{i}\right)=\frac{c\left(\tilde{s}_{i}, q_{i}\right)}{\rho} \quad \text { for each } \tilde{s}_{i} \in S_{i} \\
\left(p_{i}\left(s_{i}, q_{i}\right)-c\left(s_{i}, q_{i}\right)\right) \cdot \hat{x}_{i}\left(q_{i}, p_{i}\left(s_{i}\right)\right) \cdot \tau\left(s_{i}\right)=h_{s_{i}}\left(s_{i}, q_{i}\right), \text { if } s_{i} \in(0,1), \text { and } \\
\int_{0}^{s_{i}}\left(\frac{p_{i}\left(\tilde{s}_{i}, q_{i}\right)-c\left(\tilde{s}_{i}, q_{i}\right)}{\beta q_{i}}-\frac{\theta c\left(\tilde{s}_{i}, q_{i}\right)}{q_{i}}\right) \cdot \hat{x}_{i}\left(q_{i}, p_{i}\left(\tilde{s}_{i}, q_{i}\right)\right) \cdot \tau\left(\tilde{s}_{i}\right) d \tilde{s}_{i}=h_{q_{i}}\left(s_{i}, q_{i}\right), \text { if } q_{i} \in(0,1),
\end{gathered}
$$

Each of these conditions implies that at the margin, the benefit from increasing each decision variable equals its cost. More importantly, to be consistent with the assumptions of monopolistic competition, we have to check that the impact of a change of price, quality and size of the market area on the demand is negligible (Dixit and Stiglitz, 1977). Hence we look at the impact of a change in the choice variables on the price index $P$. The independence of market areas allows us to evaluate the elasticity $\partial \log P / \partial \log p_{i}$ and $\partial \log P / \partial \log q_{i}$ that are of the order $1 / M$, and the elasticity of $\partial \log P / \partial \log s_{i}$ that is of the order $\beta / M$. Hence, assuming $M$ is reasonably large we can neglect the effect of $p_{i}, q_{i}$ and $s_{i}$ on $P$. 
Substituting (6) into (7) and (8), and using (3) in (8), we obtain:

$$
\begin{gathered}
\beta \cdot c\left(s_{i}, q_{i}\right) \cdot \hat{x}_{i}\left(q_{i}, c\left(s_{i}, q_{i}\right) / \rho\right) \cdot \tau\left(s_{i}\right)=h_{s_{i}}\left(s_{i}, q_{i}\right), \text { if } s_{i} \in(0,1) \\
(1-\theta) C\left(s_{i}, q_{i}\right) / q_{i}=h_{q_{i}}\left(s_{i}, q_{i}\right), \text { if } q_{i} \in(0,1)
\end{gathered}
$$

From (9), firm $i$ 's per-unit variable profit $\left(p_{i}\left(s_{i}, q_{i}\right)-c\left(s_{i}, q_{i}\right)\right)$ is equal to $\beta c\left(s_{i}, q_{i}\right)$ and, by the same token, its total variable profit is $\beta C\left(s_{i}, q_{i}\right)$. Similarly, using (10),

$$
(1-\theta)=\left(\partial R_{i} / \partial q_{i}-\partial C_{i} / \partial q_{i}\right) /\left(C_{i} / q_{i}\right)
$$

where $R_{i}$ indicates firm $i$ 's total revenues. Therefore, in both equations the left-hand side represents the percentage markup over variable costs, i.e., the marginal benefit from a change in $s_{i}$ and $q_{i}$, while the right-hand side denotes the respective marginal costs. Equations (9) and (10) suggest that the solution is interior only if $h_{s_{i}}\left(s_{i}, q_{i}\right)>0$ and $h_{q_{i}}\left(s_{i}, q_{i}\right)>0 .^{5}$

Proposition 1 Under spatial price discrimination, when $h_{s_{i}}\left(s_{i}, q_{i}\right)=0$, a firm serves the entire market; when $h_{s_{i}}\left(s_{i}, q_{i}\right)>0$, it can be profitable for the firm to limit the size of the market area. When the solution is internal, a firm's optimal choice is described by equations (6), (9) and (10).

Market equilibrium. Monopolistic competition implies that firms enter the market until profits go to zero. Zero-profit condition assures that variable profits equal fixed costs. Hence:

$$
\beta C\left(s_{i}, q_{i}\right)=h\left(s_{i}, q_{i}\right)
$$

We look for an internal, unique and symmetric solution where $x_{i}=x^{*}, p_{i}=p^{*}, s_{i}=s^{*}$ and $q_{i}=q^{*}$.

Lemma 1 For each optimizing firm, $C\left(s^{*}, q^{*}\right)$ is weakly concave in $s^{*}$, that is, $C\left(s^{*}, q^{*}\right) / s^{*} \geq$ $\partial C\left(s^{*}, q^{*}\right) / \partial s$.

Combining (9), (10) and (12), we obtain:

$$
h\left(s^{*}, q^{*}\right)=s^{+} h_{s}\left(s^{*}, q^{*}\right)=q^{+} h_{q}\left(s^{*}, q^{*}\right)
$$

\footnotetext{
${ }^{5}$ Throughout the paper, we assume that second order conditions are satisfied. A discussion on the second order sufficient conditions for a local maximum is in the working paper version of the paper, which is available on request.
} 
where $s^{+}:=s^{*}\left(C / s^{*}\right) /(\partial C / \partial s) \geq s^{*}$ according to Lemma 1 and $q^{+}=q^{*} \beta /(1-\theta) \gtreqless q^{*}$ if $\beta \gtreqless(1-\theta)$.

Proposition 2 Let $s^{*}$ and $q^{*}$ be internal, symmetric and unique solution, then the equilibrium condition is provided by equation (13). In equilibrium, $s^{*} \leq s^{m}:=\arg \min _{s} \bar{h}(s, q)$.

Figure 1 shows that the firms optimally choose to operate below the average cost minimizing size. Although this is a reminescent of the excess capacity equilibrium outcome in monopolistically competitive markets, Proposition 2 emphasizes the importance of transport costs in our setting, as the following corollary shows.

Corollary 1 When $g^{\prime}=0$ and $t^{\prime}=0$, then the size of the market area, $s^{*}$ coincides with the average fixed cost minimizing size, $s^{m}$.

Thus, transport costs play a crucial role in limiting the market size. Furthermore, increasing the market size entails serving more distant consumers, thereby increasing the firms' average unit costs: hence the result in Proposition $2 .{ }^{6}$ We now turn to the analysis of the optimal quality level.

Proposition 3 Let $s^{*}$ and $q^{*}$ be internal, symmetric and unique solution, then the equilibrium condition is provided by equation (13). In equilibrium, $q^{*} \leq q^{m}:=\arg \min _{q} h(s, q) / q$ when $\beta \geq 1-\theta$ and $q^{*} \geq q^{m}$ when $\beta \leq 1-\theta$.

The choice of quality is driven by the interplay between its impact on costs and consumers' preferences indicated by $\beta$. Recalling both (11) and that $\beta$ denotes the percentage markup on unit costs of production, the interpretation of Proposition 3 hinges around the trade-off between quality and quantity. When $\beta>1-\theta$ (i.e. when it is more profitable to enlarge production), each firm choose a level of quality below the cost minimizing level $q^{m}$ while the opposite holds when $\beta<1-\theta$. Proposition 3 is illustrated in Figure 2 .

Insert Figure 2 about here

\footnotetext{
${ }^{6}$ Notice that most of the literature on logistics has as its objective the minimisation of logistic costs (see, for example: Burns et al. 1985, Campbell, 1993, McCann, 1998, and Hsu and Tsai, 1999), despite the results in Proposition 2 that $s^{*}<s^{m}$.
} 
When $\beta$ is large, products are highly differentiated, i.e. consumers strongly appreciated varieties, firms enjoy greater markup on unit costs and choose to produce a lower quality. When products are highly substitutable, firms relax price competition by enhancing their product quality.

To identify the equilibrium number of firms and varieties in the long run, using the expression for the budget constraint, we can write:

$$
\int_{0}^{1} \sum_{j=1}^{N} p_{j} x_{j} d \omega=M \int_{0}^{s} p(\tilde{s}) \cdot \hat{x}(q, p(\tilde{s})) \cdot \tau(\tilde{s}) d \tilde{s}=I .
$$

Noting that the zero-profit condition (12) can be written as $(1-\rho) \int_{0}^{s} p(\tilde{s}) \cdot \hat{x}(q, p(\tilde{s}))$. $\tau(\tilde{s}) d \tilde{s}=h$, and exploiting symmetry, we have:

$$
M^{*}=\frac{(1-\rho) I}{h\left(s^{*}, q^{*}\right)}, \quad N^{*}=s^{*} M^{*}=\frac{(1-\rho) I}{h\left(s^{*}, q^{*}\right) / s^{*}} .
$$

As expected, the number of firms is increasing in the consumer income $I$ and is decreasing in the elasticity of substitution $\sigma=1 /(1-\rho)$ and fixed costs $h$.

\section{$2.2 \quad$ Firm supply under uniform price}

In this section, firms charge the same price to the consumers in their market areas. The profit function is the same of equation (5) but the first order condition for price now yields:

$$
\bar{p}_{i}=\frac{\bar{c}\left(s_{i}, q_{i}\right)}{\rho}
$$

where $\bar{c}\left(s_{i}, q_{i}\right)=\int_{0}^{s_{i}} c\left(\tilde{s}, q_{i}\right) \tau(\tilde{s}) d \tilde{s} / \int_{0}^{s_{i}} \tau(\tilde{s}) d \tilde{s}$ is the average unit cost weighted by transport costs.

The remaining first order conditions are:

$$
\begin{gathered}
\left(\bar{p}_{i}-c\left(s_{i}, q_{i}\right)\right) \cdot \hat{x}_{i}\left(q_{i}, \bar{p}_{i}\right) \cdot \tau\left(s_{i}\right)=\frac{\partial h\left(s_{i}, q_{i}\right)}{\partial s_{i}}, \text { and } \\
\frac{s_{i} \bar{\tau}\left(s_{i}\right)}{\beta q_{i}}\left(\bar{p}_{i}-\bar{c}\left(s_{i}, q_{i}\right) \cdot(1-\beta \theta)\right) \cdot \hat{x}_{i}\left(q_{i}, \bar{p}_{i}\right)=\frac{\partial h\left(s_{i}, q_{i}\right)}{\partial q_{i}},
\end{gathered}
$$

where $\bar{\tau}\left(s_{i}\right)=\frac{1}{s_{i}} \int_{0}^{s_{i}} \tau(\tilde{s}) d \tilde{s}$. Consider the zero-profit condition:

$$
s_{i} \cdot\left(\bar{p}_{i}-\bar{c}\left(s_{i}, q_{i}\right)\right) \cdot \hat{x}_{i}\left(q_{i}, \bar{p}_{i}\right) \bar{\tau}\left(s_{i}\right)=h\left(s_{i}, q_{i}\right) .
$$


Now, substituting equation (16) into (17), (18) and (19), and after some simplifications, we obtain that:

$$
\begin{gathered}
\left(\frac{\bar{c}\left(s_{i}, q_{i}\right)}{\rho}-c\left(s_{i}, q_{i}\right)\right) \cdot \hat{x}_{i}\left(q_{i}, \bar{p}_{i}\right) \cdot \tau\left(s_{i}\right)=h_{s_{i}}\left(s_{i}, q_{i}\right), \text { if } s_{i} \in(0,1) \\
s_{i}(1-\theta) \bar{c}\left(s_{i}, q_{i}\right) \hat{x}_{i}\left(q_{i}, \bar{p}_{i}\right) \bar{\tau}\left(s_{i}\right)=q_{i} h_{q_{i}}\left(s_{i}, q_{i}\right), \text { if } q_{i} \in(0,1) \\
s_{i} \beta \bar{c}\left(s_{i}, q_{i}\right) \hat{x}_{i}\left(q_{i}, \bar{p}_{i}\right) \bar{\tau}\left(s_{i}\right)=h\left(s_{i}, q_{i}\right)
\end{gathered}
$$

In spatial price discrimination, $h_{s_{i}}\left(s_{i}, q_{i}\right)>0$ is a necessary condition for firms to limit their reach. This is no longer necessary under uniform pricing. Assume that $h_{s_{i}}\left(s_{i}, q_{i}\right)=0$. Thus, first order condition (20) is satisfied when $\bar{c}\left(q_{i}, s_{i}\right)=\rho c\left(s_{i}, q_{i}\right)$. Under uniform prices, firms may decide to limit their coverage when their unit costs are increasing in the reach. Notice that if $h_{s_{i}}\left(s_{i}, q_{i}\right)=0$, and unit variable $\operatorname{costs} c\left(s_{i}, q_{i}\right)$ are independent of $s_{i}$, then the firm chooses not limit its market coverage and $\tau\left(s_{i}\right)$ does not affect such a decision.

Proposition 4 Under uniform prices, it can be profitable for the firm to limit the size of the market area when:

- $h_{s_{i}}\left(s_{i}, q_{i}\right)>0$ or

- $h_{s_{i}}\left(s_{i}, q_{i}\right)=0$ and unit variable costs, $c\left(s_{i}, q_{i}\right)$, are increasing in the reach.

When the solution is internal, the firm's optimal choice is described by (16), (20) and (21).

To obtain the market equilibrium outcome under symmetry $\bar{p}^{u}, s^{u}, q^{u}, M^{u}$ and $N^{u}$, combine the first order and zero-profit conditions (16), (20), (21) and (19):

$$
\begin{aligned}
h\left(s^{u}, q^{u}\right) & =s^{u} \cdot\left(\frac{\bar{\tau}\left(s^{u}\right)}{\tau\left(s^{u}\right)} \frac{\partial h\left(s^{u}, q^{u}\right)}{\partial s}+\left(c\left(s^{u}, q^{u}\right)-\bar{c}\left(s^{u}, q^{u}\right)\right) \cdot \bar{\tau}\left(s^{u}\right) \cdot \hat{x}\left(s^{u}, \bar{p}^{u}\right)\right) \\
& =q_{u}^{+} \frac{\partial h\left(s^{u}, q^{u}\right)}{\partial q}
\end{aligned}
$$

The quality condition is exactly the same as in the spatial price discrimination case. Furthermore, Corollary 1 still holds. In the more general case, the convexity of $\tau(s)$ and $c(s, q)$ yields $\bar{\tau}(s) / \tau(s)>1$ and $c(s, q)-\bar{c}(s, q)>0$. Both effects lead to the equilibrium outcome that it is optimal to limit the size of the market area, in addition to the role played by economies of size in $h$. That is, relative to the spatial price discrimination case, transport 
costs and unit variable costs of production affect the optimal market size when the firms can only charge a uniform price. Moreover, the first effect is relevant only if $h_{s}(s, q)>0$, while the second one plays a role even if $h_{s}(s, q)=0$. The contrasting outcome arising under the two different pricing schemes is due to the possibility that spatial price discrimination enables the firms to pass the increases in production costs on to the consumers. The number of varieties and the number of firms are expressed as in (15) with $s^{*}, q^{*}, M^{*}$ and $N^{*}$ replaced by $s^{u}, q^{u}, M^{u}$ and $N^{u}$. It follows that $M^{*} \lesseqgtr M^{u}$ if $h\left(s^{*}, q^{*}\right) \gtreqless h\left(s^{u}, q^{u}\right)$ and $N^{*} \lesseqgtr N^{u}$ if $h\left(s^{*}, q^{*}\right) / s^{*} \gtreqless h\left(s^{u}, q^{u}\right) / s^{u}$.

\section{Social Optimum, Market Area and Quality}

To study the circumstances under which the previous analysis yields a social optimum, we follow Dixit and Stiglitz (1977) who consider “.. a rather surprising case where the monopolistic competition equilibrium is identical to the optimum constrained by the lack of lump sum subsidies (p. 301)". In the constrained socially optimum outcome they derive, the impossibility to use taxation and lump sum transfers to and from consumers and firms, suggests that the social planner is an industry regulator whose power does not extend beyond the industry. However, such a regulator can decide upon the relevant market variables, thereby achieving a constrained social optimum.

In the present setting, in order to maximize utility (and therefore social welfare), the regulator chooses each firm's price $p^{r}$, reach $s^{r}$, quality or standard $q^{r}$, the number of firms on the market $M^{r}$, having the consumer budget and the zero-profit condition as constraints.

We solve the regulator's problem for the case in which $c$ does not depend on $s$. Thus, spatial price discrimination and uniform pricing coincide due to the fact that consumers' transport costs are of the iceberg type (Fujita and Thisse, 2002, Ch. 9; Hsu, 1979). We assume that $\sum_{j=1}^{N} \tau_{j}$ is constant among consumers, i.e. they have on average identical transport costs.

Proposition 5 When $g^{\prime}(s)=0 \forall s, M^{u}=M^{*}=M^{r}, p^{u}=p^{*}=p^{r}, s^{u}=s^{*}=s^{r}$ and $q^{u}=q^{*}=q^{r}$.

Proof. The regulator chooses quantities to maximize $q\left(\sum_{j=1}^{N}\left(t_{j} x_{j}\right)^{\rho}\right)^{1 / \rho}$ subject to $\sum_{j=1}^{N} x_{j}=I / p$, yielding $x_{j} / \tau_{j}=x_{g} / \tau_{g}=: k$. After replacing this in the utility function, it emerges that $u=k q\left(\sum_{j=1}^{N} \tau_{j}\right)^{1 / \rho}$. The total welfare function is obtained by integrating 
over consumers:

$$
W=k q \int_{0}^{1}\left(\sum_{j=1}^{N} \tau_{j}\right)^{\frac{1}{\rho}} d \omega=k q\left(M \int_{0}^{s} \tau(\tilde{s}) d \tilde{s}\right)^{\frac{1}{\rho}}
$$

where the last equality holds because $\sum_{j=1}^{N} \tau_{j}$ is constant.

Aggregating over consumers yields the budget constraint $\int_{0}^{1} \sum_{j=1}^{N} p_{j} x_{j} d \omega=M p \int_{0}^{s} x(\tilde{s}) d \tilde{s}=$ $I$, while the zero-profit condition requires that: $(p-c) \int_{0}^{s} x(\tilde{s}) d \tilde{s}=h$. Combining previous equations we have the regulator's constraint:

$$
\int_{0}^{s} x(\tilde{s}) d \tilde{s}=\frac{I-M h}{c M}
$$

Noting that $k=x_{j} / \tau_{j}$ is constant for every $j$, replacing (25) into (24) yields:

$$
W=q \frac{\int_{0}^{s} x(\tilde{s}) d \tilde{s}}{\int_{0}^{s} \tau(\tilde{s}) d \tilde{s}}\left(M \int_{0}^{s} \tau(\tilde{s}) d \tilde{s}\right)^{\frac{1}{\rho}}=\frac{q}{c}(I-M h)\left(M \int_{0}^{s} \tau(\tilde{s}) d \tilde{s}\right)^{\beta} .
$$

Finally, taking the first order conditions with respect to $M, S$ and $q$, we obtain equivalent solutions to (15), (13) and (23):

$$
M^{r}=\frac{(1-\rho) I}{h\left(s^{r}, q^{r}\right)}, \quad \frac{h\left(s^{r}, q^{r}\right)}{s^{r}}=\frac{\bar{\tau}}{\tau} \frac{\partial h\left(s^{r}, q^{r}\right)}{\partial s}, \quad \frac{h\left(s^{r}, q^{r}\right)}{q^{r}}=\frac{\beta}{1-\theta} \frac{\partial h\left(s^{r}, q^{r}\right)}{\partial q} .
$$

\section{Concluding Remarks}

In this paper, we have derived the conditions under which a firm chooses to limit its market size, for the case of two different pricing rules. Under spatial price discrimination, we find that a firm limits the size of its market area only when fixed costs are increasing in the reach. Alternatively, in the case of uniform prices, it emerges that increasing variable costs may be sufficient to induce firms to limit their reach, even if fixed costs are not affected by the spatial coverage. Finally, we have shown that the monopolistic competitive equilibrium is constrained socially optimal; i.e., it yields a level of price, quality and market reach which is equivalent to the solution to the problem solved by an industry regulator.

With regards to the literature on international trade, our framework can provide an additional explanation to the overestimation of the trade flows obtained by gravity models, as 
in McCallum (1995). These models usually estimate a demand function where the quantity demanded is a decreasing function of transport costs. From the present theoretical perspective, a lack of trade is not only due to increasing variable transport costs induced by the presence of borders, but, also, to increasing fixed costs, which induce firms to limit their market coverage and not to offer their products internationally.

More generally our findings could be usefully extended to formally introduce trade areas into international trade models. Our set-up hinges on the hypothesis that all firms preferences are independent; however, it is possible to identify some main geographical, cultural and linguistic areas within which groups of firms prefer to operate. When limiting the reach is a profitable option, our findings imply that removing the trade area is unlikely to yield any benefits if the size of the area is larger than the optimal reach. Thus, our model suggests that policy intervention should focus on the causes that lead firms to limit their reach, that is, on the factors affecting the transport costs on both the firms' and the consumers' sides.

\section{References}

[1] Anderson, S.P., de Palma, A., 2000, From local to global competition, European Economic Review, 44, 423-448.

[2] Anderson, J.E., van Wincoop, E., 2001, Borders, trade and welfare, NBER WP 8515.

[3] Bandyopadhyay, U., 1999, Trade and the distribution sector: some evidence from OECD countries, Canadian Journal of Economics, 32, 1299-1312.

[4] Bramanti A., 2007, Il distretto del legno-mobile-arredo in Brianza. Prospettive future tra rischi e opportunità. Fondazione Fiera Milano, Scheiweller, Milan.

[5] Burns, L.D., Hall, R.W., Blumenfeld, D.E., Daganzo, C.F., 1985, Distribution strategies that minimize transport and inventory costs, Operations Research, 33, 369-490.

[6] Campbell, J.F., 1993, One-to-many distribution with transshipments: An analytic model, Transportation Science, 27, 330-340.

[7] Dixit, A.K., Stiglitz, J.E., 1977, Monopolistic competition and optimum product diversity, American Economic Review, 67, 297-308.

[8] Drezner, T., Drezner, Z., 1996, Competitive facilities: market share and location with random utility, Journal of Regional Science, 36, 1-15. 
[9] Fujita, M., Thisse, J.-F., 2002, Economics of Agglomeration; Cities, Industrial Location and Regional Growth, Cambridge University Press, Cambridge.

[10] Grossman, G.M., Shapiro, C., 1984, Informative advertising with differentiated products, Review of Economic Studies, 51, 63-81.

[11] Hart, O.D., 1985, Monopolistic competition in the spirit of Chamberlin: A general model, Review of Economic Studies, 52, 529-546.

[12] Helpman, E., Krugman, P.R., 1985, Market structure and foreign trade, Cambridge, MA: MIT Press.

[13] Hotelling, H., 1929, Stability in competition, Economics Journal, 39, 41-57.

[14] Hsu, S.-K., 1979, Monopoly output under alternative spatial pricing techniques: comment, American Economic Review, 69, 678-679.

[15] Hsu, C.-I., Tsai, I.J., 1999, Logistics cost, consumer demand, and retail establishment density, Papers in Regional Science, 78, 243-263.

[16] Katsikeas, C.S., Morgan, R.E., 1994, Differences in perceptions of exporting problems based on firm size and export market experience, European Journal of Marketing, 28.

[17] Katsikeas, C.S., Morgan, R.E., 1998, Exporting problems of industrial manufacturers, Industrial Marketing Management, 27, 161-177.

[18] Kedia, B.L., Chhokar, J., 1986, Factors inhibiting export performance of firms: An empirical investigation. Management International Review, 26, 33-43.

[19] Kohlberg, E., 1983, Equilibrium store locations when consumers minimize travel time plus waiting time, Economics Letters, 11, 211-216.

[20] Krugman, P.R., 1980, Scale economies, product differentiation, and the pattern of trade, American Economic Review, 70, 950-959.

[21] Laffont, J., Tirole, J., 1990, Optimal bypass and cream skimming, American Economic Review, 80, 1041-1051.

[22] McAuley, A., 1993, The perceived usefulness of export information sources, European Journal of Marketing, 27, 52-64. 
[23] McCallum, J., 1995, National borders matter: Canada-U.S. Regional Trade Patterns, American Economic Review, 85, 615-623.

[24] McCann, P., 1998, The economics of industrial location: A logistics-costs approach (Springer, New York).

[25] Ottaviano, G., Puga D., 1998, Agglomeration in the global economy. A survey of the "new economic geography," World Economy, 21, 707-731.

[26] Parr, J.B., 1995, The economic law of market areas: A further discussion, Journal of Regional Science, 35, 599-615.

[27] Piga, C.A., Poyago-Theotoky J., 2005, Endogenous R\&D Spillovers and Locational Choice", Regional Science and Urban Economics, 35, 127-139

[28] Rabino, S., 1980, An examination of barriers to exporting encountered by small manufacturing companies, Management International Review, 20, 67-74.

[29] Rauch, J.E. 1996, Networks versus markets in international trade, NBER WP 5617.

[30] Reitzes, J., 1992, Quality choice, trade policy, and firm incentives, International Economic Review, 33, 817-835.

[31] Shaked, A., Sutton, J., 1987, Product differentiation and industrial structure, Journal of Industrial Economics, 36, 131-146.

[32] Wong, S.C., Yang, H., 1999, Determining market areas captured by competitive facilities: A continuous equilibrium modeling approach, Journal of Regional Science, 39, $51-72$. 


\section{Appendix}

Proof of Lemma 1. From (6) and (2), $C\left(s^{*}, q^{*}\right)=\int_{0}^{s^{*}} c\left(\tilde{s}, q^{*}\right) \cdot \hat{x}\left(q^{*}, c\left(\tilde{s}, q^{*}\right) / \rho\right) \cdot \tau(\tilde{s}) d \tilde{s}$ $=k \int_{0}^{s^{*}}[t(\tilde{s}) / g(\tilde{s})]^{1 / \beta} d \tilde{s}$, where $k=q^{(1-\theta) / \beta} X(\rho P)^{1 /(1-\rho)}$. Being, $t / g$ weakly decreasing in $s$ and positive, $C$ is weakly concave in $s^{*}$. For the mean theorem, $\int_{0}^{s^{*}}(t(\tilde{s}) / g(\tilde{s})) d \tilde{s} / s^{*} \geq$ $\left(t\left(s^{*}\right) / g\left(s^{*}\right)\right)$.

Proof of Corollary 1. Note that $s^{+}=s^{*}$. From (13), $h\left(s^{*}, q^{*}\right) / s^{*}=h_{s}\left(s^{*}, q^{*}\right)$ and hence $s^{*}=s^{m}$. 


\section{Figures}

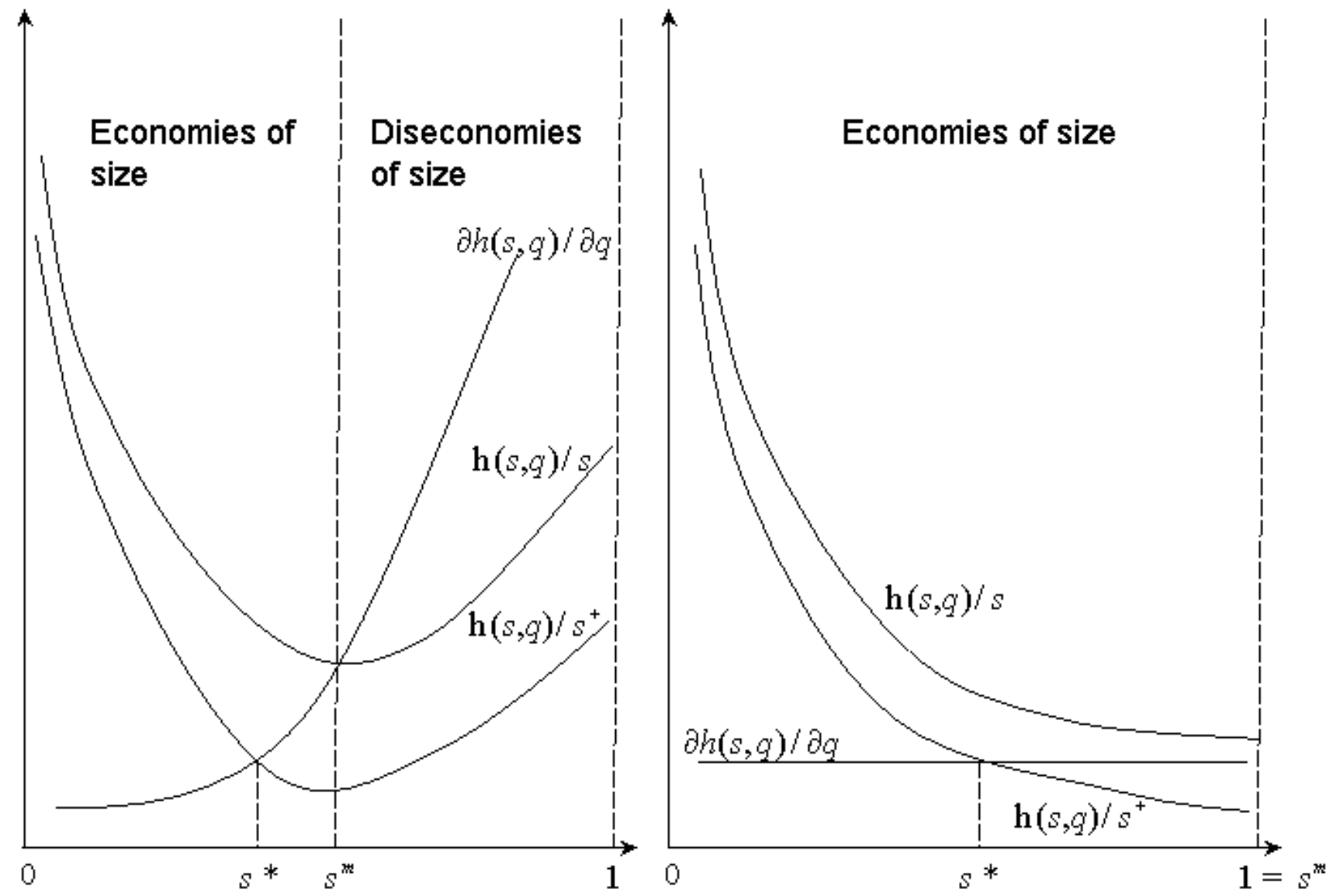

Figure 1. In Panel (a), there are diseconomies of size in the range $\left[0, s^{m}\right]$ and economies of size in the range, $\left[s^{m}, 1\right]$. In Panel (b), there are only economies of size. In equilibrium, $s^{*} \leq s^{m}$. 


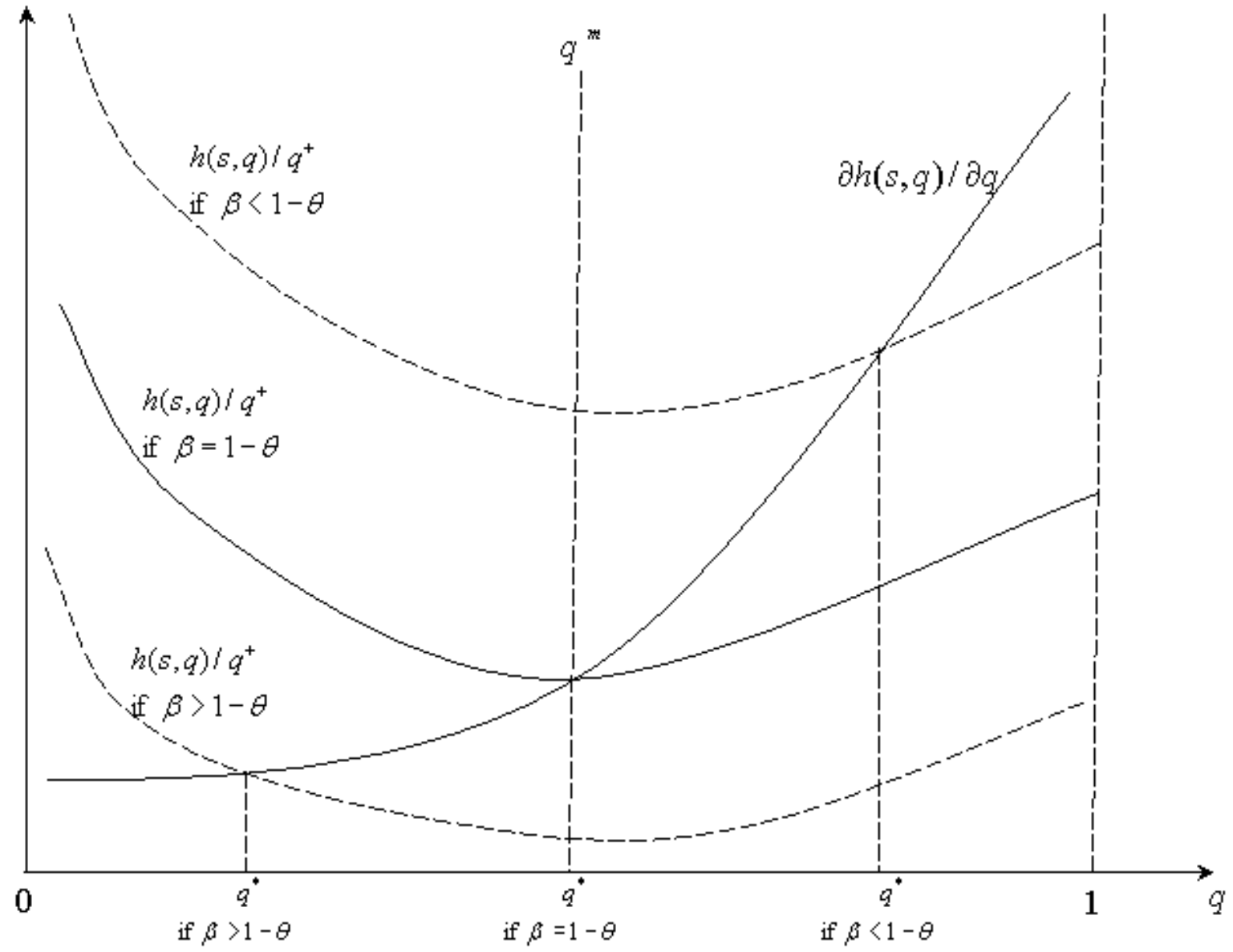

Figure 2. Quality choice. There are two situations: $q^{*} \leq q^{m}$ when $\beta \geq 1-\theta$ and $q^{*} \geq q^{m}$ when $\beta \leq 1-\theta$. 


\section{Second order conditions.}

We present the second order sufficient conditions for a local maximum, under spatial price discrimination and under uniform pricing.

Spatial price discrimination. The Hessian of the spatial price discrimination problem has infinite uncountable dimention as it includes the derivatives with respect to $p^{*}(\tilde{s}), \tilde{s} \in S=[0, s]$. To compute the second order conditions, we divide the interval $S$ into $L$ sub-intervals indixed by $l=1 . . L$, each of length $s / L=d s$. Let be $\tilde{s}_{l}:=s(l-1 / 2) / L$ and $p_{l}^{*}:=p^{*}\left(\tilde{s}_{l}\right)$. Notice that for $L \rightarrow \infty$, the function $\sum_{l=1}^{L} \mathcal{I}_{[(l-1) \cdot d s, l \cdot d s)} p_{l}^{*}$ converges to $p^{*}(\tilde{s})$. The Hessian evaluated at the stationary point is:

$$
H\left(q^{*}, s^{*}, p^{*}\right)=\left(\begin{array}{ccc}
-A \frac{h_{q}}{q^{*}}-h_{q q} & \frac{h_{s}}{q^{+}}-h_{q s} & v^{T} \\
\frac{h_{s}}{q^{+}}-h_{q s} & -h_{s} \gamma-h_{s s} & 0 \\
v & 0 & \Lambda
\end{array}\right)
$$

where $\gamma=\frac{1}{\beta} \frac{d}{d s}\left(\frac{c}{t}\right) \frac{t}{c} \geq 0, A=\frac{(1-\theta)+(1-\rho) \theta^{2}+(3 \theta-2) \rho}{(1-\theta)(1-\rho)}, \Lambda=\operatorname{diag}\left(d^{2} \pi / d p_{l}^{2}=-\frac{x(1+\rho)}{\beta c\left(s_{l}, q^{*}\right)} \cdot d s, l=1, . ., L\right)$ is a diagonal matrix, which is definite negative and $v=\left(d^{2} \pi / d q d p_{l}=x \theta /(\beta q) \cdot d s, l=1, . ., L\right)^{T}$ is a column-vector. Being satisfied the second order sufficient conditions is required that the determinants of the principal minors present alternate signs. In this case, we have to analyse the following conditions:(a) $H_{11}<0$, (b) $H_{11} H_{22}-\left(H_{12}\right)^{2}>0$, and (c) the elements on that diagonal matrix, $d^{2} \pi / d p_{l}^{2}$, be negative. In fact, we can disregard to check principal minors of order higher than 2 , i.e. $\left(H_{11} H_{22}-\left(H_{12}\right)^{2}\right) p_{1}^{*} \cdots p_{l}^{*}(d s)^{l}+o\left(d s^{l}\right)$ as they all present the exact sign when (b) and (c) simultaneously hold. ${ }^{7}$

Condition (a) is satisfied if $h$ is sufficiently convex, i.e.: $h_{q q} q / h_{q}>-A$ or when $A>0$, i.e. $\rho<\frac{1-\theta+\theta^{2}}{(1-\theta)(2-\theta)}, \rho$ small or $\theta$ large. Condition (b) is satisfied when:

$$
\left(A h_{q} / q^{*}+h_{q q}\right)\left(h_{s} \gamma+h_{s s}\right)>\left(h_{s} / q^{+}-h_{q s}\right)^{2}
$$

To provide an economic interpretation, we assume a specific functional form for $h$, i.e.:

$$
h=h_{0}+e^{s} q^{\delta}, h_{0}>0 \text { and } \delta \geq 1 .
$$

\footnotetext{
${ }^{7}$ Note that $o\left(d s^{l}\right)$ captures all the terms order $d s^{l+1}$ deriving from the multiplications including two elements of the vector $v$.
} 
Replacing (A3) into (A2), we have:

$$
\delta(1-\rho)\left(\rho(1-\theta)^{2}+\theta^{2}\right)-\rho^{2}(1-\theta)^{3}+A_{\delta} \cdot \gamma>0
$$

where $A_{\delta}=\beta^{2}(A \delta+\delta(\delta-1))>0$ if $A>0$ or $\delta$ is large; and the first part of the expression is positive when $\theta$ and $\delta$ are large, or $\rho$ is small.

Summing up, under perfect price discrimination, conditions (a)-(c) hold if $\theta, \delta$ and $\gamma$ are large, or $\rho$ is small.

Uniform pricing. The Hessian evaluated at the stationary point is:

$$
H\left(q^{u}, s^{u}, p^{u}\right)=\left(\begin{array}{ccc}
-A \frac{h_{q}}{q}-h_{q q} & \phi \frac{h_{s}}{q}-h_{q s} & \frac{1}{1-\rho} \frac{\theta}{1-\theta} \frac{h_{q}}{p} \\
\phi \frac{h_{s}}{q}-h_{q s} & -h_{s} \gamma_{u}-h_{s s} & \frac{1}{1-\rho} \frac{(c-\rho p)}{(p-c)} \frac{h_{s}}{p} \\
\frac{1}{1-\rho} \frac{\theta}{1-\theta} \frac{h_{q}}{p} & \frac{1}{1-\rho} \frac{(c-\rho p)}{(p-c)} \frac{h_{s}}{p} & -\frac{1}{1-\rho} \frac{1}{1-\theta} \frac{q h_{q}}{p^{2}}
\end{array}\right)
$$

where $\gamma_{u}=\left(\frac{1}{p-c} \frac{d c}{d s}-\frac{1}{\tau} \frac{d \tau}{d s}\right) \geq 0$ and $\phi=\frac{\rho}{1-\rho}\left(1-\frac{1-\rho}{\rho} \frac{\theta c}{p-c}\right)$. We have to test the following inequalities: (a') $H_{11}<0$, (b') $H_{11} H_{22}-\left(H_{12}\right)^{2}>0$, and (c') $2 H_{12} H_{13} H_{23}+H_{11} H_{22} H_{33}-H_{11} H_{23}^{2}-$ $H_{22} H_{13}^{2}-H_{33} H_{12}^{2}<0$.

Conditions (a') is the same of (a). To provide an economic interpretation of (b') and (c'), we assume that $h$ follows (A3). For condition (b'), this yields to the following inequality:

$$
\delta(A+\delta-1)\left(\gamma_{u}+1\right)-(\delta-\phi)^{2}>0
$$

Notice that in order to be satisfied, it is sufficient that: $\delta(A+2 \phi-1)>\phi^{2}$. In addition, notice that $\frac{\beta c}{p-c} \geq 1$ and $\frac{\beta c}{p-c}=1$ when $\frac{d c}{d s}=0$. When $\gamma_{u}=0$, (A6) simplifies in:

$$
\delta \frac{(\theta-\rho)^{2}+\rho\left(\theta^{2}+1-\rho\right)}{(1-\rho)(1-\theta)}-\left(\frac{(1-\theta) \rho}{1-\rho}\right)^{2}>0
$$

Hence, when $\theta$ and $\delta$ are large and $\rho$ is small, the equation is certainly satisfied. Using (A3), after some simplifications, condition (c') is satisfied when

$$
(\delta(1-\rho)-\rho(1-\theta))\left(\gamma_{u} \delta(p-c)^{2}+(1-\theta)\left(\rho p^{2}-c^{2}\right)\right)>0
$$


or when $\rho$ is small, or $\gamma_{u}$ and $\theta$ large.

Summing up, under uniform pricing, conditions (a')-( $\left.\mathrm{c}^{\prime}\right)$ hold if $\theta, \delta$ and $\gamma_{u}$ are large, and $\rho$ is small. 